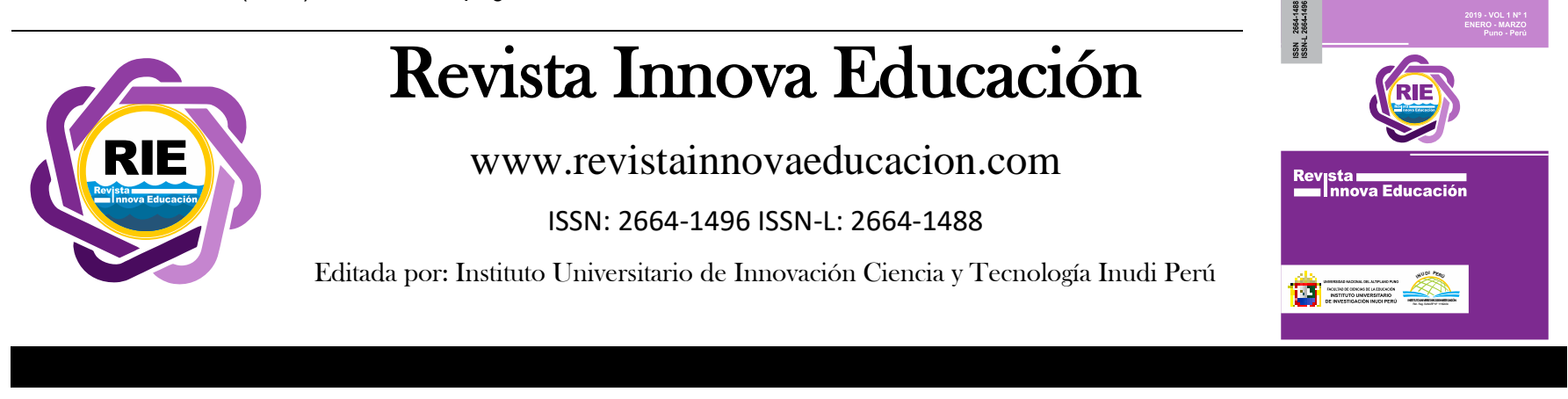

\title{
La educación intercultural y los pueblos indígenas en el Estado de Guerrero, México
}

\author{
Intercultural education and indigenous peoples in the State of Guerrero, Mexico
}

\author{
Ana Castillo ${ }^{1}$ \\ Universidad Hipócrates, Acapulco de Juárez-Guerrrero, México \\ (D) https://orcid.org/0000-0003-0351-2725 \\ Carlos Cuevas $^{2}$ \\ Universidad Hipócrates, Acapulco de Juárez-Guerrrero, México \\ (D) https://orcid.org/0000-0002-5168-1753
}

DOI: https://doi.org/10.35622/j.rie.2020.02.002

Recibido 20/03/2020/ Aceptado 19/04/2020 Publicado 26/04/2020

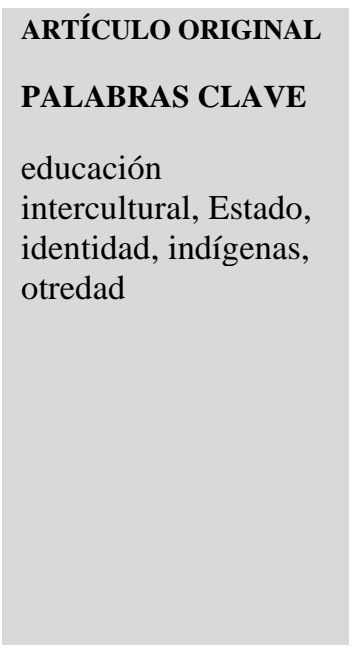

\section{KEYWORDS}

intercultural education, State, identity, indigenous, otherness.

\begin{abstract}
Resumen: El artículo sostiene que la educación intercultural emancipa a los pueblos indígenas y contribuye a la construcción de una democracia dialógica. Además, señala que la escuela juega un papel importante, puesto que promueve el respeto al Otro, fomenta saberes y aprendizajes más horizontales entre los estudiantes y docentes. Pero, también indica que la falta de presupuesto, la burocracia, la discriminación y el rechazo a la cultura no occidental impiden la construcción de una nueva escuela. Dicho esto, el propósito de este trabajo consiste en analizar la situación actual de los pueblos indígenas y la educación en el estado de Guerrero. La discusión sobre este tema permite que los actores educativos y la sociedad reconsideren el hecho de que el diálogo intercultural refuerza el sentido de pertenencia y de identidad de aquellas comunidades como los amuzgos, mixtecos, nahuas y tlapanecos, quienes se han visto en situación de marginalidad durante estos últimos decenios. En cuanto a la metodología, nos apoyamos en la sociología reflexiva e interpretativa con la finalidad de llevar a cabo un análisis minucioso de las fuentes bibliográficas y hemerográficas, pero también de las complejidades, posibilidades y paradojas del sistema educativo mexicano.
\end{abstract}

\footnotetext{
${ }^{1}$ Correspondencia: docente.sep03@gmail.com

${ }^{2}$ Correspondencia: cuerocar@hotmail.com
}

Summary: The article maintains that intercultural education emancipates indigenous peoples and contributes to the construction of a dialogical democracy. In addition, he points out that the school plays an important role, since it promotes respect for the Other, fosters more horizontal knowledge and learning among students and teachers. But it also indicates that the lack of budget, the bureaucracy, the discrimination and the rejection of non-western culture impede the construction of a new school. That said, the purpose of this work is to analyze the current situation of indigenous peoples and

(c) (1) 
education in the state of Guerrero. The discussion on this topic allows educational actors and society to reconsider the fact that intercultural dialogue reinforces the sense of belonging and identity of those communities such as the Amuzgos, Mixtecos, Nahuas and Tlapanecos, who have been marginalized. during these last decades. Regarding the methodology, we rely on reflective and interpretive sociology in order to carry out a detailed analysis not only of bibliographic and newspaper sources, but also of the complexities, possibilities and paradoxes of the Mexican educational system

\section{INTRODUCCIÓN}

México es uno de los países con mayor riqueza cultural y lingüística; entre éstas se encuentran los hablantes del náhuatl, mixteco, zapoteco, tlapaneco, amuzgo, entre otros (INEGI, 2010). Sin embargo, la mayoría de estas lenguas están a punto de desaparecer debido a las condiciones sociales y económicas precarias que subsisten en estas comunidades. Además, la falta de empleo y la desigualdad han obligado a que mucho de estos indígenas se hayan visto forzados a abandonar sus tierras y buscar oportunidades laborales en las grandes ciudades. A esta problemática se suma la discriminación y la falta de reconocimiento de los llamados Otros, es decir pueblos indígenas, como parte de la nación mexicana (Kapuscinski, 2007; Todorov, 1991). Esta situación se puede vislumbrar en espacios o campos de instrucción pública como son las escuelas, sobre todo, rurales. Allí, la práctica docente, la actividad académica que lleva a cabo el estudiante y la administración docente que se hace cargo de la capacitación, elaboración y reproducción de programas curriculares (occidentales) se encuentran barnizadas por la trama compleja de la sociedad de mercado. Con base en esto, no sólo se educa al ciudadano, sino también se construye una idea de rechazo a toda cultura o forma social que impida la reproducción del sistema de mercados y mercancías para un mundo altamente competitivo. Nos referimos a la otredad. Se trata de una categoría que ha servido para comprender el sometimiento de la cultura occidental sobre el resto del mundo. En otras palabras, estamos hablando de la dominación que ha sufrido el indio, conocido peyorativamente, de parte del colonizador.

Esta idea de dominación se encuentra presente en todos los centros educativos de instrucción oficial. La negación hacia el Otro, vale decir, el profesor o estudiante proveniente de una cultura no occidental, tiene que enfrentarse a todo un canon discursivo que se encuentra impregnado no sólo en los planes y programadas de estudio, sino también en el corazón mismo del sistema educativo. La escuela (rural) más allá de incluir a los sujetos o agentes educativos los obliga a formar parte de una ciudadanía desigual y combinada (Muñoz, 2001). Es más, el Estado no apuesta por la interculturalidad como un proceso de diálogo de las culturas y construcción de 
una democracia desde las diferencias y por la igualdad social y económica (Schmelkes, 2003). Al contrario, promueve paradójicamente la aculturación. Ésta tiene que ver justamente con aquella idea que el Estado (multicultural) sí acepta la diferencia o existencia de las culturas, pero no admite la inclusión del Otro en la consolidación de la democracia o en la participación de los circuitos económicos y políticos mundiales (García, 1999; Bauman, 1999; Fuller, 1992). Al respecto, Fornet-Betancourt (2009) señala que la intervención del indio en el escenario económico siempre ha sido de marginación y en la política sólo se ha encargado de reproducir en apariencia un lenguaje igualitario de derechos civiles y políticos.

Más allá de este discurso que es propio del capitalismo multicultural, es importante señalar que a pesar de que México sea un país diverso aún persiste el sometimiento de los pueblos indígenas. El Estado y su proyecto político de inclusión de los Otros no sólo pretende reconocer, valorar y promover el uso de las lenguas no occidentales, sino también considera que la educación es la mejor vía para lograr su integración como ciudadanos. Nos parece que esta idea ha sido una agenda presente para el aparato estatal como la Secretaria de Educación Pública durante, por lo menos, estas últimas décadas. Todos los proyectos educativos dirigido a las poblaciones más vulnerables como las comunidades indígenas han cumplido con el propósito de reconocer parte de su historia, pero los esfuerzos y propuestas realizadas han sido magros, porque no se ha llevado a cabo ningún reconocimiento a la diferencia cultural y mucho menos político (Stavenhagen, 1996; Sánchez, 1999; Saladino 1995; Ortiz, 2004; Benjamin, 2002).

Este hecho se llevó a cabo durante el siglo veinte e inicios de este siglo. Por ejemplo, en la actualidad las políticas públicas dirigidas a los pueblos indígenas tienen como objetivo la eliminación de la desigualdad y la inequidad económica y social. Incluso se ha realizado una modificación al Art. $3^{\circ}$ de la Constitución donde se hace referencia a la obligatoriedad en la educación secundaria, pero en la realidad quedan excluidos los intereses de las comunidades indígenas, porque no se brindan las condiciones económicas, así como la infraestructura necesaria para llevar a cabo procesos de aprendizaje reales y acordes a las necesidades de cada región. A decir verdad, no se protegen las lenguas indígenas o los usos y costumbres de las comunidades indígenas a pesar de que existe una campaña turística nacional e internacional de que México es un país diverso e inmerso en una lógica mundial de intercambio de mercancías.

A pesar de que el nuevo modelo educativo en vigor promete romper los nudos de desigualdad la situación del acceso a la educación oficial es más compleja de la que parece. Para 
obtener buenos resultados, se debe considerar el hecho de que la equidad y la inclusión deben ser principios transversales en todo el sistema educativo (Emiret et. al., 2018). Todo esto, debe realizarse con la finalidad de que la cultura y las lenguas indígenas tomen su valor como sistemas de pensamiento y de comunicación. Cabe indicar que a pesar de que modelo presume ser incluyente, es necesario que se realicen actividades dentro y fuera del aula alusivas a estos principios para que se reconozcan los aportes de las distintas culturas originarias de cada estado y sean transmitidas desde todos los actores educativos. De este modo se podría plantear las bases de una educación intercultural.

\section{MÉTODO Y MATERIALES}

El método que se aborda en este trabajo tiene dos aspectos a resaltar: primero, la consideramos como un proceso de desfetichización de las categorías (Estado, cultura, escuela, programas curriculares, entre otros) que deben de ser cuestionadas a partir de la realidad en la cual se producen (Kosik, 1967). Segundo, tomamos como punto de partida la sociología reflexiva (Bourdieu y Passeron, 2005) y la sociología interpretativa (Weber, 1992; 1984; 1982) con la finalidad de comprender los elementos constitutivos de la educación y los pueblos indígenas en el estado de Guerrero. Para ello, nos servimos de la teoría weberiana con los ánimos de explicar la acción social y política que se establece a partir de la idea de Estado. Esto ha permitido concebir la manera cómo la racionalidad política y la estructuración social responde a aspectos históricos y racionales del individuo. Esta "forma racional de existencia no garantiza en nada la libertad humana, por el contrario, es el individuo quien debe asumir las contrariedades de esta sociedad" (Acuña, 2015, p. 228). Es decir, toda superposición política de una cultura sobre la otra en una nación diversa como México no puede ser pensada sin la acción racionalizadora del sujeto (occidental) sobre el Otro. En ese sentido, nos parece que la escuela en tanto campo social y político cumple un papel fundamental en la legitimación de esa racionalidad dominadora. Para develar estas ideales/racionales de la sociedad contemporánea, hemos tratado de reconstruir la idea de educación desde abajo, es decir, desde las formas cómo se organiza y reproduce el saber en escenarios donde pervive un entramado étnico complejo. Además, siguiendo a Marx (2005, p. 21) nos hemos apoyado de la teoría crítica con la necesidad de "reemprender el viaje de retorno" y ver al interior de las paradojas de la educación en Guerrero una "rica totalidad con múltiples determinaciones y relaciones" pedagógicas y culturales. Nos referimos a aquellos pueblos indígenas que han puesto en cuestionamiento toda realidad reificada o condicionada por el tiempo de la económica neoliberal. No en vano, Benjamin (2008, p. 307) insiste en que se debe "retener una imagen del 
pasado como la que imprevistamente se presenta al sujeto histórico en el instante mismo del peligro".

\section{RESULTADOS Y DISCUSIONES}

\section{a) Repensando el Estado y la construcción del Otro}

El presente apartado parte de la necesidad de interpretar la relación compleja que existe entre Estado y sociedad civil, así como comprender de mejor manera los procesos interétnicos que se desarrollan en el estado de Guerrero. Partimos de la idea de que es necesario apelar a la razón histórica, porque se trata de un recurso epistémico importante que nos permite ahondar sobre aquellos procesos y acontecimientos que dan lugar a los dilemas, paradojas y habitáculos de una sociedad como la guerrerense. Se trata de una invitación para repensar el Estado en su relación con el Otro y, sobre todo, conocer la situación actual de la educación intercultural. En este caso, nos referimos al mundo indígena, vale decir, aquel mundo que ha sido marginado y retirado de los grandes relatos de la historia mexicana. Sin duda se trata de un mundo desgarrado, pero que también ha puesto en vigencia su memoria histórica.

En la jerga académica eurocéntrica el Otro, en mayúscula, es una categoría (capitalistamulticultural) que ha servido para catalogar o racializar al sujeto (Zizek, 1998). El Otro es un ser desprovisto de actitudes y aptitudes para afrontar la modernidad (Bartra, 2013). A decir verdad, para el progreso el Otro no forma parte de la psique occidental sino de un pensar mitológico, sufrido y condenado (Fanon, 1994). En esta misma temática, Edgar Lander (2003, p. 12) sostiene que esta diferencia es considerada como la imposición de un "pensamiento hegemónico" científico donde la razón no solo ha bifurcado al cuerpo para llegar a hechos más concretos, sino también se ha cartografiado e impuesto una relación de fuerza y dominación entre Occidente y los otros mundos. Además, señala que se requiere, sin duda alguna, interpelar una "narrativa histórica" propia de una sociedad moderna y capitalista ya que, además de naturalizar las relaciones sociales, naturaliza el saber humano. Otro planteamiento que pone en tela de juicio el campo de la hegemonía epistémica proviene de Aníbal Quijano (2003, pp. 201-223), quien señala que esta relación de distancia y ruptura es "un elemento de colonialidad en el patrón de poder hoy mundialmente" reproducido y objetivado; lo dicho se vincula con el hecho de que la ruptura radical del sujeto entre mente y cuerpo abordada por Descartes (2015) en su Discurso del método fue aplicado para América y, también, acaso para oriente. A partir de ésta se empezó a construir occidente y la modernidad. De este modo, se puede decir que la mano de obra-no remunerada, “india", formaba parte del engranaje de las relaciones sociales de explotación en el mundo. Por esta razón se estableció un patrón de dominación hegemónico y que hoy se reproduce en todos los 
escenarios que son controlados por las altas esferas del poder. La escuela es el lugar idóneo para poner en vigencia esta imposición cultural e ideológica.

Esta visión es clave para entender el pensamiento occidental, porque da origen al nacimiento del Otro folclórico y no real. Dicha experiencia puede ser oteada a partir del debate sobre la condición del indio entre Bartolomé de las Casas (2005), el obispo de Chiapas, y Juan Ginés de Sepúlveda a finales del siglo XVI. Sepúlveda señalaba que, siguiendo la tesis aristotélica, existían personas destinadas a servir a otros. Tal debate hizo entrever que el mundo europeo era el único hemisferio capaz de producir conocimiento y el resto del mundo era inferior de pensar racionalmente (Weber, 1984). Visto esto, la tradición o la cultura de los Otros no serían reconocidas como formas de pensamiento moderno debido a que la totalidad epistémica o eurocéntrica impide la emergencia y el dialogo del pensamiento Otro. Bajo estas circunstancias el pensamiento subalterno se convierte en un problema ético, pues se trata de defender el despojo cultural (mental) que han sufrido los pueblos indígenas y, sobre todo, porque existe la necesidad de reescribir otra narrativa ab initio que exprese el grito de Todas las sangres (Arguedas, 1998). En ese sentido, la tarea pedagógica intercultural debe tratar de recuperar aquella memoria indígena que ha sido víctima de la historia represiva/hegemónica; a su vez, ésta debe promover un orden justo reconociendo al Otro su dignidad y su capacidad de compartir e imaginar otros mundos.

La cuestión indígena viene a ser ese gran colofón que requiere ser atendido como una cuestión epistémica. No se trata de folklorizar a los sujetos que hablan una lengua distinta a la oficial o mucho menos se trata de dar a conocer a los indígenas como héroes rurales. Al contrario, la idea central consiste en develar y sacar a la luz aquellos elementos constitutivos que están generando marginación y desigualdades políticas, económicas y, sobre todo, educativas. En relación con esto, a grosso modo, partiendo del siglo veinte y de la llamada "revolución mexicana" es necesario indicar que la construcción del nuevo Estado-nacionalista fue impulsada por los de abajo, es decir, por los indios y vaqueros (suelen llamar así a los habitantes rurales del sur y norte algunos intelectuales conocedores de la cultura política mexicana). El “problema del indio"-punto de partida de J.C. Mariátegui (2008) para entender el capitalismo no europeo- no solo marcó a México, sino también a todas las regiones de América Latina. En pleno siglo veinte y bajo la consolidación de los estados-nación pervivía aún una relación social de tipo patrimonial que se compenetraba con el progreso. El Estado-finquero, el Estado-gamonal o el Estado-bananero era la expresión de esa relación entre feudalismo y capitalismo al mismo tiempo en México y América Latina. En ese sentido, en la nación mexicana la urgencia de un desborde popular era necesario, 
puesto que pervivía la necesidad de reorganizar la sociedad y redistribuir la riqueza concentrada en manos de los hacendados y los clanes familiares.

El Estado cumplía un papel fundamental en el sometimiento de las poblaciones indígenas. En México, el ascenso de Porfirio Díaz al poder implicó una serie de reacciones políticas de parte de los vencidos. La necesidad de construir otro poder con los más humildes hizo que se generara una retahíla rebelde que se desarrolló en 1910 por los convencionistas (Zapata y Villa, para ser precisos). Este suceso, dice Adolfo Gilly (1994) en La revolución interrumpida, culminó en una revolución que reorganizó las relaciones sociales políticas y de trabajo, pero que quedó inconclusa. Es decir, en esencia el despliegue de una lucha campesina mexicana de inicios del siglo veinte no emancipaba al campo sino la sometía a condiciones laborales más complejas. Es más, nos atrevemos a decir que el problema del indio aún está presente. La relación con el Estado es de dominación y resistencia. Subsisten aspectos, hechos y paradojas que no se han desvanecido aún.

La revolución devino marginación y homogenización de la sociedad. El propósito de crear un Estado-nación o un nacionalismo mexicano iba acorde con el proyecto de modernización. Esto implicaba que todos los sectores sociales formaran parte de una sola identidad, de una sola nación que avance y mire hacia adelante. No en vano, por ejemplo, la preocupación de muchos académicos como José Vasconcelos (2009), quien estuvo a cargo de la Secretaria de Educación Pública, se centraba en encontrar en La raza cósmica un ser social mestizo, todopoderoso, un Prometeo del futuro. Para esto era necesario combatir el analfabetismo, fomentar la escuela rural y la educación media superior. Homogeneizar culturalmente toda instancia educativa. Dicho propósito parte de la idea de que la educación era considerada como una instancia importante en el mantenimiento del statu quo y la legitimación de la coerción social.

Durante setenta años de priismo (1929-1999), desde Plutarco a Zedillo, el Estado llevó a cabo políticas para impulsar la integración social y cultural de los pueblos campesinos, aquellos quienes se habían organizado para emanciparse junto a Zapata y Villa. Bajo esta vorágine, en 1948, por ejemplo, el INI (Instituto Nacional Indigenista), hoy conocido como CDI (Comisión Nacional para el Desarrollo de los Pueblos Indígenas), nació con la finalidad de combatir el subdesarrollo mediante la industrialización de las tradicionales formas de producción y reproducción campesina (proletarización campesina), así como considerar la lengua indígena como un elemento importante en la incorporación del individuo a la sociedad de mercado. Esta postura se robusteció a inicios de los años ochenta cuando el Estado desarrollista o keynesiano agonizaba y se daba un giro hacia el 
Estado neoliberal. A partir de esta nueva forma estatal se llevaron a cabo reformas económicas y, sobre todo, educativas, pues, debían responder a las necesidades de un mundo en expansión y altamente competitivo.

La emergencia del Estado neoliberal dio cabida para que se concretara un nuevo pacto social. No obstante, el papel prioritario del Estado siempre fue la articulación de la sociedad de trabajadores para la economía capitalista. Bajo este paradigma el Estado siempre consideró como un eje fundamental la participación de la educación como detonadora del progreso desde finales del siglo XX. Esto implicaba no solo brindar herramientas conceptuales y analíticas al estudiante, sino también dotarlo de competencias laborales para que puedan afrontar las vicisitudes y necesidades del globo. Este hecho provocó que se fomentara la privatización de la educación, así como la privatización de las empresas públicas. A esto se sumó la modificación del Art. 27 de la Constitución, pues la intención era repartir las tierras y, sobre todo, fomentar el desvanecimiento y proletarización de las comunidades. El resultado de esto culminó en un amplio rechazo de parte de los indígenas. Nos referimos al levantamiento del EZLN (Ejército Zapatista de Liberación Nacional) y su lucha no solo para cuestionar la ola de privatización que padecía el país, sino también para exigir la cancelación del TLC con Estados Unidos en 1994.

Este desencuentro entre indígenas y Estado culminó con la realización de los Acuerdos de San Andrés. En dicho acuerdo, el EZLN exigía que se discutieran los derechos y la cultura indígena, la democracia y la justicia, el bienestar y desarrollo, la conciliación en Chiapas, así como los derechos de las mujeres. De otro lado, esta lucha hizo que se diera apertura al movimiento político indígena, surgiera una reinvención del indio, se produjera alianzas entre los pueblos indígenas para detener la avanzada neoliberal y pusiera en el centro del debate la idea de autonomía y pedagogía del caracol.

\section{b) La educación intercultural en Guerrero}

La interculturalidad y el proceso educativo en el estado de Guerrero tienen que ser visto desde la razón histórica. Esto no implica quedarnos atrapados en el tiempo y que no podamos pensar la actualidad y lo que aqueja a la educación y la escuela. Al contrario, nos parece que para abrir la discusión en torno a tan complejo tema es necesario acercarnos a ciertos acontecimientos que han formado parte de la memoria indígena. Los indígenas del estado de Guerrero han tenido una relación difícil y de resistencia con el poder oficial. Así, por ejemplo, la Constitución de 1857 
hizo que los llamados indios se convirtieran en ciudadanos. Este cambio respondía a los intereses de la clase dominante, puesto que ésta consideraba que para afianzar el poder y legitimar su dominación como tal, la escuela debía convertirse en un mecanismo importante de integración nacional. La subordinación político-cultural a través de la educación ha servido para legitimar el discurso hegemónico y justificar la postración de los pueblos indígenas. Para ello, había que crear una nueva identidad que pasara por la lengua y la educación. Dicha creación de valores culturales implicaba la negación al Otro (Moya, 1998).

Bajo este contexto, pensamos que es necesario ahondar más en el tema que nos ocupa: la intercultural. Para ello es necesario recordar la categoría indígena y su relación con el poder. Durante la Intendencia de México, en 1808, se crearon "escuelas de lenguas indígenas" y estaban bajo la administración de los padres o comunidades indígenas. Se sabe que existieron 20 escuelas tanto en Chilapa como en Tixtla. El referente más importante de la educación indígena en Guerrero data desde 1932 y fue implementado por el Centro de Integración Social (CIS) de San Gabrielito, municipio de Tepecoacuilco; posteriormente, se crearon otras escuelas como en Atenango del Río y Alcozua (González, 2009, p. 259).

En 1948 se creó el Instituto Nacional Indigenista (INI), así como los Centros de Coordinadores Indigenistas (CCI). De este modo se inició la educación bilingüe intercultural en Guerrero. El primer CCI fue creado en Tlapa de Confort en 1963. El propósito del proyecto era reclutar a promotores bilingües. "Como promotores bilingües, debía atender a niños de 4, 5, 6 y hasta más años de edad, mediante un programa que se llamó Grado preparatorio, pues los preparaban para ingresar a la primaria federal o estatal castellanizándolos durante un año, es decir, su papel fundamental era que los niños aprendieran a hablar el español” (González, 2009, p. 237). En muchos casos los promotores no tenían estudios concluidos y lo que hizo el Estado fue crear el programa Educación para todos. Posterior a ésta se creó el Instituto Federal de Capacitación Magisterial, no fue sino hasta mediados del año 2003 donde se reclutaba a jóvenes para que enseñaran en las comunidades indígenas; de otro lado, la mayoría de estos jóvenes contaban con estudios de bachillerato y posteriormente culminaban sus estudios en la Universidad Pedagógica Nacional y en la Normal Regional de Tlapa (González, 2009, p. 238). Actualmente, la educación indígena en Guerrero depende de la Dirección de Educación Indígena (DEI-SEP). En otras palabras, ésta consta de: 
14 jefatura de Zona del Nivel de Educación Primaria y 10 del Nivel Preescolar, con 92 supervisores escolares y una supervisión de niños migrantes. De aquellos 102 promotores culturales bilingües que iniciaron educación indígena en Guerrero en el año de 1964, para el año escolar 2002-2003, han pasado a ser 5934 docentes, que atienden a 126273 alumnos de diferentes niveles y servicios educativos en 1639 centros de trabajo: Educación inicial indígena, Preescolar indígena y Primaria Intercultural Bilingüe, así como los servicios de apoyo: albergues escolares, centros de integración social, centros de educación para niños migrantes. Todos estos servicios educativos y apoyos a la educación indígena están ubicados en 769 comunidades que incluyen 39 municipios de 80 que existen en el estado de Guerrero. (González, 2009, p. 239)

Según INEGI (2010) en México existe cerca de 6.9 millones de indígenas. La población del estado de Guerrero es de 3079349 millones de personas. De estos el $19.86 \%$ de 15 a más años no sabe leer; el $7.9 \%$ de 6 a 14 años no asiste a clases. Acapulco tiene una población de 722 499 habitantes: 347722 son varones y 374647 son mujeres. Las cuatro lenguas indígenas que existen son el mixteco, el amuzgo, el tlapaneco y el nahua. Dicho esto, se sabe que la población indígena es de 700 mil habitantes y los afromexicanos son alrededor de 200 mil habitantes. Los nahuas representan el 40\% de la población y se encuentran en La Montaña, Sierra Central y Cuenca superior del río Balsas, Sierra norte y Tierra Caliente. La población de mixtecos representa el 28 $\%$ de la población indígena y se ubican en la parte alta de La Montaña. Los tlapanecos representan el 22\%; y los amuzgos representan el 9\% de la población indígena. Estos últimos se encuentran en Xochistlahuaca, Tlacoachistlahuaca, Zocoalpa, Cosuyoapan, Chocoapan, Huehuetano, El Pájaro y Las Minas. Por último, los afromexicanos representan el $6.5 \%$ de la población en Guerrero.

En Guerrero y en comparación con otros estados el 33.9 \% de la población es indígena; en Oaxaca el 65.7 \% de la población es indígena; en Yucatán el 65.4\% de la población es indígena; y en Tamaulipas el 6.3\% de la población es indígena (Plan Estatal de Desarrollo, 2016). Además, más de la mitad de la población indígena en Guerrero es analfabeta. Esta problemática se pude ver en Cochoapa el Grande 56.1\%; Metlatónoc, 43\%; Aleozauca de Guerrero 42.3\%; José Joaquín 37.3\%; Xalpatlahuac 36.1\%; etc (Plan Estatal de Desarrollo, 2016).

Dicho esto, en el estado de Guerrero las comunidades indígenas que han migrado han sido las comunidades amuzgas y tlapanecas. Estas culturas prehispánicas descienden de la Costa Chica, al sur del estado, y se han movilizado a otros espacios con la finalidad de encontrar mejores oportunidades laborales y superar la ola de marginación, violencia y desempleo. Si bien este fenómeno se está dando en muchas regiones del estado, creemos que los amuzgos y tlapanecos, 
quienes se encuentran en la localidad de Ejido Nuevo, municipio de Acapulco, y provenientes de localidades como Xochistlahuaca, nos referimos a uno de los territorios más pobres de México, pues en este lugar los indicadores de desarrollo humano sólo son equiparables a otros escenarios como África, padecen de manera crónica los efectos devastadora de la crisis neoliberal y global.

Cabe resaltar que esta problemática nos obliga a considerar seriamente que la cultura sea entendida como algo no estático, porque ésta cambia y su riqueza depende de sus miembros y de la manera cómo las lenguas edifican tempo-espacialidades dialógicas que van más allá de la lógica del Estado (neoliberal). Pero, esto no es posible si el Estado considera que la cultura es inerte y no viviente. Sobre todo, se aleja de todo propósito reivindicativo porque desecha el diálogo de las culturas y propone una cultura dialógica y estructurada por planes, programas y políticas universales. Con esto, creemos que el Estado es una forma y relación social, puesto que se encarga de legitimar las relaciones sociales, económicas y de reproducción del capital (Hirsch, 2005).

Lo expuesto arriba se presente como un problema, porque no se promueven o existen espacios donde se fomente el diálogo cultural y se revalore la lengua indígena. Al contrario, el propósito es generar una hegemonía cultural y lingüística en todos los escenarios posibles. Desde luego esto nos llama la atención poderosamente, porque se trata de dominar las verdaderas necesidades de las poblaciones marginadas. Un reflejo de ello, es el hecho de que poco a poco los indígenas del sur que se han asentado en Ejido Nuevo, se trata de un lugar que se encuentra en las afueras del Puerto, han optado por dejar de lado su lengua materna y se han aferrado a su segunda lengua, el español. A esto se suma el hecho de que la burla, el desconocimiento, las críticas y el rechazo a sus orígenes indígenas representan acciones cotidianas y políticas que se imponen desde arriba y se reproducen en ciertos aparatos ideológicos como la escuela (Althusser, 1995). Debido a esto, los indígenas del sur han elegido esconderse y hablar sus lenguas entre la misma familia y dentro de sus hogares. Lo que más llama la atención del efecto que produce la dominación cultural, es saber cómo la identidad en estos lugares se ha convertido en un acto de rechazo y negación y no como algo emancipatorio. Basta saber que las familias de origen indígena miran a su propia lengua como un asunto de exclusión. Por supuesto, esta postura ha traído como consecuencia que sus descendientes, quienes asisten a las escuelas, se vean avergonzados y se abstengan de aprender y reproducir sus lenguas, todo esto para encajar en una sociedad única y líquida (Bauman, 2003).

Dentro de las instituciones educativas se ha observado cómo los jóvenes que provienen de familias con habla indígena se sienten rechazados, discriminados e incluso avergonzados por su 
identidad. Este tipo de sentimientos producidos por sus mismos compañeros los conduce a tomar ciertas actitudes introvertidas, de timidez, de tristeza, de exclusión, de inferioridad, de vergüenza y pena (Bartra, 1998; 1999; 2011). En este sentido, es necesario que se incluyan espacios de convivencia y relaciones interculturales donde se promuevan la diversidad cultural el diálogo, la equidad y la democracia entre todos los integrantes de una sociedad. Esto ayuda a construir una sociedad pacífica y dialógica, ausente en uno de los estados más martillados por la política neoliberal.

\section{CONCLUSIONES}

¿Cómo educar bajo estas circunstancias? ¿Cómo promover la educación intercultural en un contexto en el que todo parece indicar que solo existe una cultura dominante, la globalización? ¿Cómo fomentar una pedagogía intercultural que rompa con el eurocentrismo educativo? La tarea no es tan fácil de decir, pero tenemos que animarnos a proponer una alternativa. Nos parece oportuno proponer la ruptura epistemológica del saber. Es decir, se tiene que revalorar la cultura indígena y su lengua, porque ha sido el sector más martillado por la historia. En Guerrero las comunidades de amauzos, tlapanecos, nahuas y mixtecos son las más marginadas. La educación oficial que reciben dista mucho de sus formas de actuar, pensar y sentir el mundo. El discurso inclusivo que promueve el Estado no ha resuelto los problemas complejos como la desigualdad económica o política, la libertad y la autonomía. Al contrario, el Estado a través de sus políticas multiculturales se ha encargado únicamente de reconocer la existencia de las etnias, pero no las hace partícipes de la construcción de otra democracia y, mucho menos, de una escuela nueva (para todas las sangres). En las escuelas no se fomenta el respeto al Otro, sino se mira con distancia al sujeto no occidental o de habla indígena. Además, los programas (interculturales) pensados para las zonas rurales no están siendo pensadas desde el interior mismo de cada realidad o cultura, sino desde la realidad occidental y del dominador, acaso colonizador.

La reflexión y la crítica resultan claves para interpretar los procesos de generación de conocimientos en los pueblos indígenas y la manera como éstos establecen un disloque con la cultura dominante. Dicho esto, es importante desarrollar un argumento que aborde el antagonismo entre el pensar subalterno y el pensar hegemónico o, a decir verdad, la oposición teórica entre el canon epistemológico occidental y no-occidental por ser éste último un elemento de importancia para la construcción de un proceso de enseñanza y aprendizaje con rostro intercultural. Ante todo, 
es necesario cuestionar la epistemología occidental para referirnos a aquellas subjetividades que se siguen reproduciendo en un espacio y tiempo-histórico.

Este cuestionamiento se da en una multiplicidad de formas de pensar y de hacer. Esto implica cuestionar que el pensar no es exclusividad de un centro o un mundo occidental, sino de un hacer que sabe del conflicto en el que está en juego la realidad por construir y hacer más horizontal. En otras palabras, la filosofía no eurocéntrica es un saber propio de todos los tiempos y de todas las culturas. El conocimiento no sólo se refiere al análisis de los sistemas complejos de formas de razonar sino, sobre todo, a un saber hacer realidad. En definitiva, la educación intercultural no sólo es una propuesta pedagógica, sino todo un presupuesto histórico de justicia. Su labor consiste en el hacer del diálogo de las culturas, puesto que ésta permite impugnar aquellos hábitos y contenidos simbólicos occidentales que transgreden las formas de socialización y de pensamiento Otro no reconocido por las escuelas.

\section{REFERENCIAS BIBLIOGRÁFICAS}

Acuña, J. K. (2015) Michael Löwy: Max Weber y las paradojas de la modernidad. Nóesis. Revista de Ciencias Sociales y Humanidades, 24 (48), 227- 232.

Althusser, L. (1995). Ideología y aparatos ideológicos del Estado. México: Ediciones Quinto Sol. Arguedas, J. M. (1998). Todas las sangres. Madrid: Alianza Editorial.

Bartra, A. (2013). Hambre/Carnaval, dos miradas a la crisis de la modernidad. México: UAMXochimilco.

Bartra, R. (1998). El Salvaje en el espejo. México: Unam-ERA.

Bartra, R. (1999). La sangre y la tinta: Ensayos sobre la condición postmexicana. México: Océano.

Bartra, R. (2011). El mito del salvaje. México: FCE.

Bauman, Z. (1999). La globalización. Consecuencias humanas. Buenos Aires: F.C.E.

Bauman, Z. (2003). Modernidad líquida. México: Fondo de Cultura Económica.

Benjamin, Thomas (2002) ¡Primero viva Chiapas! La Revolución Mexicana y las rebeliones locales. En Mario Humberto Ruz y Juan Pedro Viqueira (editores). Chiapas. Los rumbos de otra historia (pp. 175- 194). México: Universidad Nacional Autónoma de México.

Benjamin, W. (2008). Obras. Libro I/Vol. 2. Madrid: Abada Editores.

Bourdieu, P., y Wacquant, L. (2005). Una invitación a la sociología reflexiva. Buenos Aires: Siglo XXI.

De las Casas, B. (2005.). Brevíssima relación de la destruyción de las Indias. Madrid: Editorial EDAF.

Descartes, R. (2015). Discurso del método. España: Pluton Ediciones.

Emiret, V., Guillén R., y Galindo, C. (2018). Situación y diagnóstico de la educación en México: perspectivas y posibilidades. México: STUNAM. 
Fanon, F. (1994). Los condenados de la tierra. México D.F: Fondo de Cultura Económica.

Fornet, R. (2009). La filosofía Intercultural. En Enrique Dussel, Eduardo Mendieta y Carmen Bohórquez (eds). El pensamiento filosófico latinoamericano, del Caribe y Latino [13002000] (pp.362-376). México: Siglo XXI.

Fuller, N. (1992). La educación intercultural: retos y propuestas. Antrophológica $N^{\circ} 10$ Diciembre. Recuperado de: https://dialnet.unirioja.es/descarga/articulo/5042208.pdf

García, N. (1999). La globalización imaginada. Buenos Aires: Paidós.

Gilly, A. (1994). La revolución interrumpida. México: Era.

González, F. (2009). Todos estos servicios educativos y apoyos a la educación indígena están ubicados en 769 comunidades que incluyen 39 municipios de 80 que existen en el estado de Guerrero. Recuperado de: http://www.nacionmulticultural.unam.mx/edespig/diagnostico_y_perspectivas/recuadros/ capitulo\%207/1\%20educacion\%20indigena.pdf

Hirsch, J. (2005). ¿Qué significa estado? Reflexiones acerca de la teoría del estado capitalista.

Revista Sociologia e Política, 24, 165-175. Recuperado de: http://www.scielo.br/scielo.php?pid=S0104-

$44782005000100011 \&$ script $=$ sci_abstract\&tlng=es

INEGI. (2010). Censo de Población y Vivienda 2010. Elaborado con base en los censos de población y vivienda de 1980, 1990, 2000 y 2010. Recuperado de: www.inegi.org.mx/est/contenidos/proyectos/ccpv/default. aspx el 27/03/2012.

Kapuscinski, R. (2007). Encuentro con el Otro. Barcelona: Anagrama.

Kosik, K. (1967). Dialéctica de lo concreto. México: Grijalbo.

Lander, E. (2003). La colonialidad del saber: eurocentrismo y ciencias sociales. Argentina: CLACSO.

Mariátegui, J. C. (2008). 7 Ensayos de interpretación de la realidad peruana. Lima: Amauta.

Marx, C. (2005). Elementos fundamentales para la crítica de la economía política (Grundrisse) 1857-1858 (I). México: Siglo XXI Editores.

Moya, R. (1998). Reformas educativas e interculturalidad en América Latina. Revista Iberoamericana de Educación, 17. Recuperado de: http://www.campus-oei.org/oeivirt/ rie08.htm

Muñoz, H. (2001). De prácticas y ficciones comunicativas y cognitivas en educación básica. México: Conacyt-UPN.

Ortiz, L. (2004). El silencio como forma de resistencia civil. Análisis del discurso del EZLN, 19972001. Revista Venezolana de Economía y Ciencias Sociales, 10(1), 109-127.

Plan estatal de desarrollo 2016-2021. Recuperado de: http://www.congresogro.gob.mx/files/plan\%20estatal\%20de\%20desarrollo/estrategias_tr ansversales_ecologia_pueblos_originarios.pdf

Quijano, A. (2003). Colonialidad del Poder, eurocentrismo y América Latina. En Edgardo Lander (ed). La colonialidad del saber: eurocentrismo y ciencias sociales (pp. 201-246). Argentina: CLACSO.

Saladino, A. (1995). El problema indígena. Homenaje a José Carlos Mariátegui. México: Universidad Autónoma del Estado de México.

Sánchez, C. (1999). Los pueblos indígenas, del indigenismo a la autonomía. México: Siglo XXI. 
Schmelkes, S. (2003). Educación intercultural, ponencia presentada en el Diplomado en educación $\begin{array}{llll}\text { intercultural bilingüe. } & \text { Recuperado http:// }\end{array}$ interbilingue.ajusco.upn.mx/modules.php?name=News\&file=article \&sid=12

Stavenhagen, R. (1996). Conflictos étnicos y Estado nacional. Washington: Instituto de Investigaciones de la ONU para el Desarrollo Social.

Todorov, T. (1991). La conquista de América. El problema del otro. México, Siglo XXI.

Vasconcelos, J. (2009). Ensayo Literario Raza Cósmica. México D.F: Trillas.

Weber, M. (1992). El problema de la irracionalidad en las ciencias sociales. Roscher y Knies y los problemas lógicos de la Escuela Histórica de Economía. Madrid: Tecnos.

Weber, M. (1982). Ensayos de metodología sociológica. Sobre algunas categorías de la sociología comprensiva. Argentina: Amorrortu.

Weber, M. (1984). Economía y sociedad. Conceptos de la sociología y del "significado" en la acción social. México, D. F.: Fondo de Cultura Económica.

Zizek, S. (1998). Multiculturalismo o la lógica cultural del capitalismo multinacional. (pp.137188). En Frederic Jameson y Slavoj Zizek, S. Estudios Culturales. Reflexiones sobre el multiculturalismo (pp. 137-188). Buenos Aires: Paidós.

\section{Conflicto de intereses / Competing interests:}

Los autores declaran que no incurre en conflictos de intereses.

Rol de los autores / Authors Roles:

Ana Castillo: conceptualización, curación de datos, análisis formal, adquisición de fondos, investigación, metodología, administración del proyecto, recursos, software, supervisión, validación, visualización, escritura preparación del borrador original, escritura - revisar \& amp; edición.

Carlos Cueva: conceptualización, investigación, metodología, administración del proyecto, recursos, software, supervisión, validación, visualización, escritura - preparación del borrador original, escritura - revisar \& amp; edición.

Fuentes de financiamiento / Funding:

Los autores declaran que no recibió un fondo específico para esta investigación.

Aspectos éticos / legales; Ethics / legals:

Los autores declaran no haber incurrido en aspectos antiéticos, ni haber omitido aspectos legales en la realización de la investigación. 